
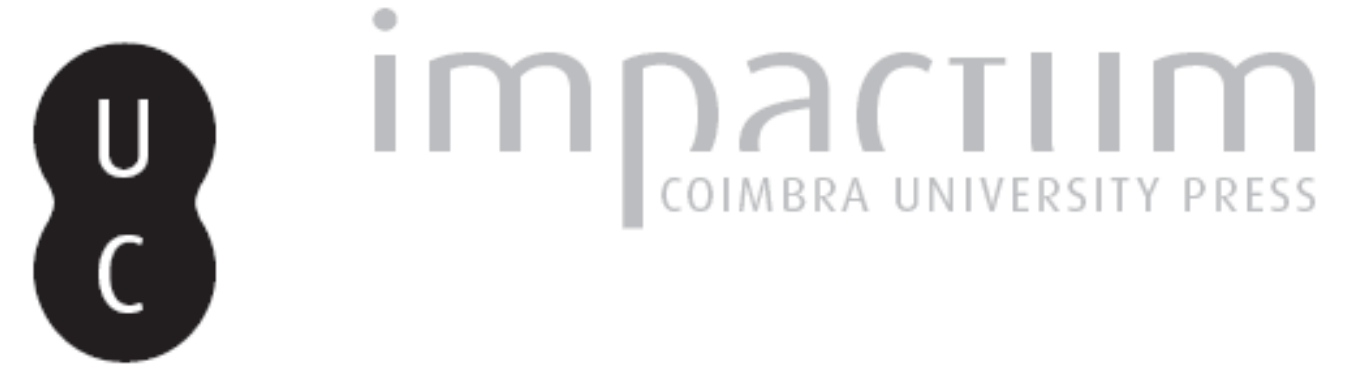

\title{
“Uma questão de Medicina, na aula de Filosofia, no Colégio das Artes: an cor humanum medio in pectore locatum sit?"
}

Autor(es): $\quad$ Urbano, Carlota Miranda

Publicado por: $\begin{aligned} & \text { Associação Portuguesa de Estudos Clássicos; Instituto de Estudos } \\ & \text { Clássicos }\end{aligned}$

URL

persistente:

URI:http://hdl.handle.net/10316.2/30351

DOI: DOI:http://dx.doi.org/10.14195/0872-2110_55_8

Accessed : $\quad$ 26-Apr-2023 11:44:25

A navegação consulta e descarregamento dos títulos inseridos nas Bibliotecas Digitais UC Digitalis, UC Pombalina e UC Impactum, pressupõem a aceitação plena e sem reservas dos Termos e Condições de Uso destas Bibliotecas Digitais, disponíveis em https://digitalis.uc.pt/pt-pt/termos.

Conforme exposto nos referidos Termos e Condições de Uso, o descarregamento de títulos de acesso restrito requer uma licença válida de autorização devendo o utilizador aceder ao(s) documento(s) a partir de um endereço de IP da instituição detentora da supramencionada licença.

Ao utilizador é apenas permitido o descarregamento para uso pessoal, pelo que o emprego do(s) título(s) descarregado(s) para outro fim, designadamente comercial, carece de autorização do respetivo autor ou editor da obra.

Na medida em que todas as obras da UC Digitalis se encontram protegidas pelo Código do Direito de Autor e Direitos Conexos e demais legislação aplicável, toda a cópia, parcial ou total, deste documento, nos casos em que é legalmente admitida, deverá conter ou fazer-se acompanhar por este aviso. 


\section{Boletim de \\ Estudos Clássicos}

Associação Portuguesa de Estudos Clássicos

Instituto de Estudos Clássicos

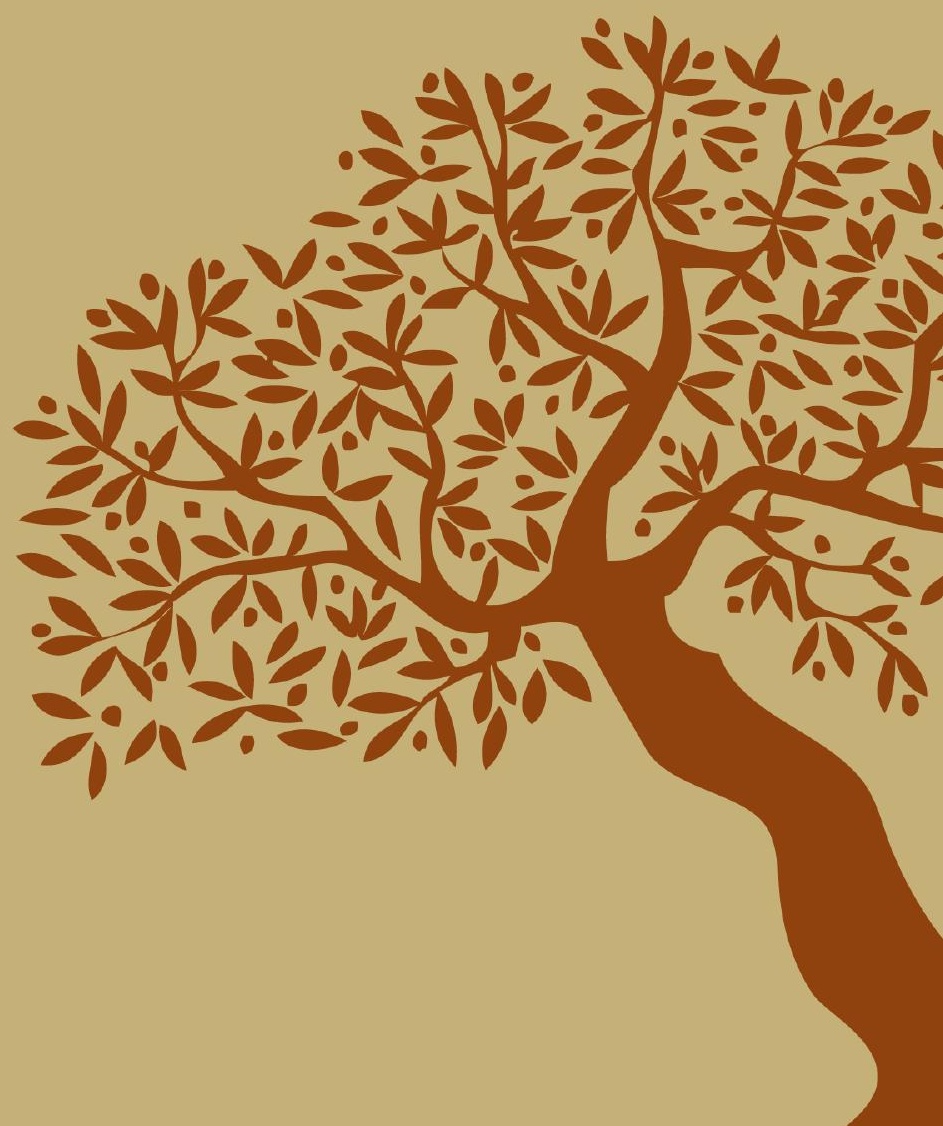

Coimbra

Junho de 2011 


\section{“UMA QUeSTÃo de MEdicina, NA AUla de Filosofia, No COLÉGIO DAS ARTES: AN COR HUMANUM MEDIO IN PECTORE LOCATUM SIT?"}

A uma visão do mundo como um cosmos organizado, coerente e perfeito corresponde uma unidade dos saberes. É à luz desta mundividência que devemos considerar os curricula de estudos dos séc. XVI e XVII, compatíveis com lições como esta que aqui trazemos. A questão que traduzimos e comentamos é da autoria do P. Francisco Mendoça, célebre professor do Colégio das Artes e prestigiado orador. Neste colégio foi professor de Retórica e de Filosofia (1604) e mais tarde Reitor (1617-1620).

Depois da sua morte, que ocorreu em 1626 em Lyon, quando regressava de Roma a Portugal, os seus irmãos do Colégio da Companhia em Coimbra publicaram um interessante volume que reúne a sua obra oratória e pedagógica, bem como os textos que os seus condiscípulos e alunos escreveram em sua homenagem. O título sugestivo que denominou este volume posteriormente reeditado foi, muito ao gosto barroco da metáfora floral, Viridarium sacrae ac profanae eruditionis: Jardim de erudição sagrada e profana. A obra compõe-se de nove livros. Os três primeiros têm por título comum Flores sacri. Segue-se o livro IV, Flores Philosophiae, o livro V Flores Varii, o livro VI Flores Eloquentiae, o livro VII Flores Rhetoricae, o livro VIII Flores Humaniorum Literarum e, finalmente, o livro IX Flores Poetici.

A questão sobre a localização do coração humano é a nº 28 do livro IV, De floribus Philosophiae, que reúne no total 47 questões. Trata-se, como uma rápida leitura do seu índice faz crer, de quaestiones diversas, provavelmente redigidas em momentos diferentes, ao longo do magistério de Mendoça, que o responsável pela edição póstuma, o P. Francisco Machado, terá coligido e agrupado de acordo com a sua natureza.

As aulas ministradas pelos professores do Colégio das Artes (portanto, também as do P. Francisco Mendoça) seguiam, como é sabido, o plano de estudos testado ao longo de décadas e finalmente passado à letra na versão 
'definitiva' na Ratio Studiorum de 1599. ${ }^{1}$ Este plano articulava os estudos das humanidades com o das matérias científicas, estudos que hoje nos habituámos a ver nos curricula seguir caminhos divergentes, se não mesmo formalmente incompatíveis. Independentemente do curso que viessem a seguir, os alunos dos Colégios da Companhia, como o Colégio das Artes ou o de Jesus em Coimbra, combinavam, pois, estudos científicos e humanísticos, movendo-se numa interdisciplinaridade 'avant la lettre'. Os alunos que este modelo educativo formava ficariam munidos, não só de uma bagagem humanística e retórica, no domínio do pensamento e da sua expressão, como de bons conhecimentos de história, literatura, geografia, de astronomia, matemática, biologia, física...

Alheio ao preconceito anti-enciclopédico, este modelo, no fundo, recriava, adequando-o ao seu tempo, o ideal humanístico ciceroniano.

O P. Francisco Mendoça, conhecido especialmente pelos seus dotes oratórios e pelos seus sermões, como acima dissemos, não ensinou apenas em Coimbra, mas também em Lisboa e em Évora. Uma das características da Companhia de Jesus, ordem originalmente missionária que várias circunstâncias ligaram profundamente ao ensino, era, precisamente, a itinerância. O membro da Companhia raramente se eternizava numa casa ou numa cátedra, a não ser que as necessidades da 'missão' o exigissem. Assim, os jesuítas circulavam pelos vários colégios da sua Província ou das missões a ela associadas ou até mesmo por colégios de outras províncias onde fossem necessários. Nos colégios portugueses, sobretudo de Coimbra e Lisboa, ensinaram jesuítas, vindos de outros reinos, que faziam 'escala' em Portugal durante um ou dois anos de preparação, antes de partirem para as missões portuguesas. Além das pessoas e dos mestres, circulavam por suas mãos também os livros, graças ao labor editorial das casas da Companhia que se esforçavam por publicar as obras dos seus melhores mestres.

O facto de pertencer a uma vasta rede escolar como era a dos colégios da Companhia (que para além da Europa atingia as Américas e o Oriente) não foi inconsequente para o ensino ministrado nos mesmos colégios, e isso é visível nesta obra do P. Francisco Mendoça que cita escrupulosa e abundantemente autores seus contemporâneos, em parte membros da mesma

1 Sobre esta matéria veja-se a recente tradução da Ratio Studiorum e o seu estudo introdutório: Miranda, Margarida, Código Pedagógico dos Jesuítas. Ratio Studiorum da Companhia de Jesus-Regime escolar e curriculum de estudos, Esfera do Caos, Lisboa, 2009. 
Companhia de Jesus. E esta citação frequente é, note-se, tanto para argumentar as teses que defende como para apresentar as teses que refuta.

Em suma, o carácter transnacional da Companhia favoreceu inegavelmente a circulação do saber, dos mestres e dos livros, e isso repercute-se naturalmente no ensino, maxime no ensino da filosofia e das ciências ditas 'naturais' que a esta altura conheciam um período de transformação conducente ao nascimento da ciência moderna.

Quando apresenta uma questão de medicina nas suas aulas de filosofia, o Padre Francisco de Mendoça herda uma longuíssima tradição no seio da qual Medicina e Filosofia natural se encontram estreitamente relacionadas. Esta relação, enraizada na Grécia Antiga, é visível, desde logo, nas obras de autores como Galeno, grande médico grego, que na verdade era também um filósofo, mas também na obra de Avicena, o médico e filósofo islâmico (9801037) que comenta a obra do mesmo Galeno. Durante o período dito medieval, os médicos responsáveis pela literatura médica de então, na sua maioria médicos formados nas universidades, escrevem também sobre filosofia natural ou a ela recorrem para qualificar e autorizar as suas obras.

Fica assim claro por que razão no De floribus philosophiae, surgem questões como esta que aqui trazemos: An cor humanum medio in pectore ita locatum sit, ut neque ad dextram declinet, neque ad sinistram? Estará o coração humano localizado no centro do peito, de tal modo que não tem qualquer inclinação nem para a esquerda nem para a direita?

A interrogação é retórica. O primeiro parágrafo consistirá em responder afirmativamente argumentando com as conveniências da localização central do coração. Só depois o mestre passa à referência das autoridades consagradas.

Quanquam in quibusdam imperfectis animantibus per totum corpus facultates permiscentur, quod non habeant exactam aut partium uarietatem, aut facultatum integritatem in perfectis tamen principales virtutes, quibus gubernatur anima, locis ac situ distribuit natura.

Embora em certos seres vivos imperfeitos as faculdades se confundam pelo corpo inteiro, de modo a que não haja neles uma divisão exacta das partes nem a totalidade das faculdades, nos perfeitos, porém, as suas principais qualidades, que governam a alma, a natureza as distribui nos seus lugares e posição.

Francisco de Mendoça prossegue partindo da divisão tripartida (que remonta a Galeno), para justificar o lugar central do coração, na posição 
'intermédia'. A faculdade vital gerada no coração separa adequadamente a faculdade animal (gerada no cérebro), da faculdade natural (gerada no fígado) para que esta não perturbe aquela e simultaneamente esteja equidistante das duas para facilmente comunicar com ambas.

Supremam sedem animalis ${ }^{2}$ facultas obtinuit, mediam vitalis ${ }^{3}$, infimam naturalis ${ }^{4}$; oportebat enim vim cogitantem ab alimenti officinis separari, ne crebri halitus intelligentiam interturbent, quod fieri solet, iuxta illud, Crassus uenter non gignit tenuem mentem.

A faculdade animal ocupa o lugar superior, a vital ocupa o intermédio e a faculdade natural ocupa o inferior; era pois necessário que a força do pensamento ficasse separada das oficinas do alimento, para que [os seus] vapores repetidos não perturbassem a inteligência, o que pode acontecer, [como naquele dito]: barriga cheia não dá ligeireza ao pensamento.

At cum spirituum uitalium calor ad opera animalis \& naturalis facultatis plurimum sit necessarius, necesse fuit inter utramque locari cor uiuifici caloris officinam, ut posset commode utrique communicari.

Mas como o calor dos órgãos vitais é deveras necessário ao trabalho das faculdades animal e natural, foi necessário que o coração ficasse localizado entre uma e outra oficina, para que pudesse com maior conveniência comunicar com as duas.

$\mathrm{Na}$ apresentação de mais argumentos, Francisco Mendoça invoca, em primeiro lugar, a autoridade de Aristóteles mas acrescenta observações de clássicos posteriores, como Plínio.

Sunt et aliae plausibiles rationes, quibus ostendi potest cor in medio pectore locari; tum ex membri dignitate, est enim cor ueluti rex ac princeps partium reliquarum, cui proinde regni in medio esse conuenit, ut bene Aristoteles loquitur lib.3.de part. Anim. Cap.4.\& lib. De iuuent. \& senect. Cap.2. Tum ex commoditate uitae, quia corporis temperamentum a corde dependet. Tum ex tuendae uitae ratione, quia opus fuit sollicitam esse naturam de membro principe, cui uel minima laesio magnum affert detrimentum; unde non fuit contenta

\footnotetext{
2 Animalis, $e$ : 'que tem alma'.

3 Vitalis, $e$ : 'coisa que dá vida'.

${ }^{4}$ Naturalis, $e$ : 'natural, conforme a natureza'.
} 
natura situm cordi in medio assignare, sed fortium \& durorum ossium apposuit munimenta, ut Plinius considerauit lib. II cap. 37.

Há ainda outros argumentos válidos com os quais se pode demonstrar que o coração se localiza no centro do peito. Quer em razão da dignidade deste órgão, pois como o coração é como que o rei, ou príncipe, das restantes partes, convém que esteja no centro do reino, como bem diz Aristóteles no livro $3^{\circ}$ do De Anima, capítulo 4 e no De iuuentute et senectute, cap. 2. Quer ainda em razão da vantagem para a vida, porque a compleição do corpo depende do coração. Quer também em razão da preservação da vida, porque foi necessário que a natureza fosse solícita para com o órgão príncipe, a quem a mínima lesão provoca grande prejuízo. Daí decorre que a natureza não se tenha limitado a colocar o coração no centro, mas além disso o tenha dotado de uma protecção de ossos duros e resistentes, como considerou Plínio (Livro II, cap.37).

Respondida a primeira parte da questão, Francisco Mendoça introduz a segunda parte: Haverá alguma inclinação do coração para um dos lados do peito? O Professor começa por indicar as teses que depois contrariará, e preocupa-se por apresentar os argumentos utilizados pelos defensores dessas teses. Adianta, desde logo, a opinião de Avicena, comentador da obra médica de Galeno. Os argumentos que refere e logo apresenta, começam por basearse em Aristóteles:

Cum igitur certum sit cor medium tenere pectus, num ad alteram eius partem aliquantulum declinet, dubitatur? Vergere ad sinistram censuit Auicena lib. 3 se.. 10. Tract. I cap. 1 \& sem. II. Cap. I de anatomia cordis. Aristotelem sequuntur omnes fere Peripatetici cum reliquo hominum vulgo; pro quibus sunt huiusmodi argumenta.

Sendo certo que o coração se encontra no meio do peito, duvidase se porventura ele se encontra inclinado para alguma das suas partes. Que ele se encontra inclinado para a esquerda é o que pensa Avicena (livro 3 De senectute 10, tratado I, cap. 1 e De senectute II cap. I do De anatomia cordis) Praticamente todos os Peripatéticos seguem Aristóteles, juntamente com o vulgo dos homens, a cujo favor temos os seguintes argumentos:

Primum. Sinistra pectoris humani pars est frigidissima, Medicorum confessione; oportuit igitur huic frigiditati consultum iri per aliquam cordis membri calidissimi inclinationem: permixtum enim calori frigus temperamentum efficit salubre; \& hac ratione utitur 
Aristoteles. Secundum, si cor humanum medio in pectore prorsus esset, coniuncta in parte dextra cordis \& hepatis caliditas animal penitus inflammat et: sed secus sit; declinat igitur cor ad laeuam.

Em primeiro lugar: A parte esquerda do peito humano é, como reconhecem os médicos, muito fria. ${ }^{5}$ Foi então necessário velar por este frio por meio de uma certa inclinação do órgão do coração que é muito quente. Juntando assim frio e calor, a temperatura torna-se saudável; é este o argumento de Aristóteles. Em segundo lugar, se o coração estivesse direito no meio do peito, concentrando-se na parte direita o calor do coração e do fígado, inflamar-se-ia profundamente; mas para que assim não aconteça, o coração inclina-se para a esquerda.

Depois destas razões, o professor acrescenta a experiência, que classifica como argumento na filosofia, mas para denunciar e justificar um erro de interpretação dessa mesma experiência.

Accedit experientia, argumentum in Philosophia. Sentimus dextrum pectoris latus esse calidius, quod ex eo prouenit, quia cor in laeuam modice declinans spiritus motu suo in dextram exsufflat; quae fuit causa, qua deceptus Ioannes de Gand. falso credidit ad 4 physic. quaest. 8 in solutione primi cor in dextram partem deflectere. Item maiorem experimur in sinisttro latere pulsationem, quam in dextro. Et haec pro hac parte.

Acresce ainda a experiência, argumento na Filosofia. Sentimos que o lado direito do peito é mais quente, e o que dele provém, porque, inclinando-se ligeiramente o coração para o lado esquerdo, com o seu movimento, o sopro vital sopra sobre o lado direito; foi esta a razão pela qual, iludido, João de Gand acreditou erradamente (n. 4 physic. Quaest. 8) na primeira solução, segundo a qual o coração estaria inclinado para o lado direito. Do mesmo modo, experimentamos a pulsação mais forte no lado esquerdo que no direito. E o inverso neste lado.

Mendoça passa agora à apresentação da sua opinião e das autoridades que a suportam. Para além de Galeno cita Tomás Rodrigues da Veiga (15131579), médico cristão-novo que foi professor na Universidade de Coimbra.

5 Entenda-se neste contexto 'inactiva', 'com pouca actividade'. Cfr. Bluteau, Raphael, Vocabulário Portuguez e Latino, Colégio das Artes da Companhia de Jesus, Coimbra, 1713, 214. 
Sed nos contrariam tuemur cum Galeno 6. De usu partium cap. $2 \&$ alibi, quem Thomas a Vega sequitur lib. De art. Med. Cap. 28 \& Medici alii, qui afferunt cor in medio thoracis spatio ita ad amussim situm esse, ut neque ad dextram, neque ad sinistram, neque sursum, neque deorsum declinet. Argumenta sunt. Cor in medio omnino pectore existens in loco est, ut ait Galenus, tum ad firmitatem aptissimo, tum ad recipiendam aequalem toto ex pulmone refrigerationem maxime opportuno; Nec est ulla in declinatione commoditas: non est igitur cur sedes prorsus media illi denegetur.

Mas nós pensamos o contrário, com Galeno (De usu partium cap. $2 \&$ alibi) que Tomás da Veiga também segue (De art. Med. Cap. 28) juntamente com outros médicos, que afirmam que o coração se encontra precisamente no centro do tórax e que não sofre nenhuma inclinação nem para a direita nem para a esquerda, nem para cima nem para baixo. E os argumentos são estes: encontrando-se o coração precisamente no centro do peito, está num lugar, como diz Galeno, não só adequadíssimo para a sua estabilidade, como propício para receber uma igual respiração de todo o pulmão. Não há, pois, qualquer conveniência na sua inclinação, nem há qualquer razão para que lhe seja recusado esse lugar precisamente central.

De novo volta a Aristóteles para provar que esta tese não o contradiz, mas que a diferença das partes direita e esquerda do corpo se justificam com o movimento.

Nam quod Aristotelis ait, laeuam frigidae esse naturae, retorqueri in ipsum potest: quoniam opus est, ut in animalibus praesertim homine, pars sinistra frigida sit; datur enim in locali animalis motu pars una ueluti quiescens, cui motio innitatur; altera agilis ac velox, a qua facile motio prodeat: ut autem temperatura frigida ad quietem est aptissima; ita calida ad motum: quare non debent esse paria sinistra dextris.

Com efeito, aquilo que diz Aristóteles, que o lado esquerdo é de sua natureza frio, pode ser usado para este mesmo argumento: pois é necessário que, como nos animais, com maioria de razão no homem, a parte esquerda seja fria; com efeito, diz-se que no movimento local do animal, por um lado, uma parte como que repousa, nela se apoiando o impulso; por outro lado, a outra parte é ágil e veloz, para que dela possa surgir facilmente o impulso: enquanto a temperatura fria está associada ao repouso, a quente, por seu lado, está associada ao 
movimento. É por essa razão que o lado direito não é igual ao esquerdo.

Quae ratio cum in omni animali locum habet, tum multo maxime in homine, qui ad exercendas artes frequentissima eget dextrae partis motione sinistra quiescente. Deinde in reliquis animalibus, quae fere solo motu progressivo exercentur, non est tam euidens partium imparitas; \& tamen in ipsis cor prorsus in medio est: ergo, \&c. Sed inter omnes grauius urget pro hac parte anatomica 6 experientia, quae in medio prorsus pectore humanum cor situm reperit.

Esta regra verifica-se em todo o ser vivo, e com mais razão no homem que, para exercer as suas artes, necessita muito frequentemente do impulso do lado direito, enquanto o esquerdo descansa. Por isso, nos restantes animais, que quase só exercem o movimento progressivo, não é tão evidente a desigualdade das duas partes. E, no entanto, mesmo neles o coração está precisamente no centro. Mas o argumento que pesa mais entre todos a favor desta parte é a experiência anatómica, que encontra o coração precisamente no meio do peito.

Da leitura desta questão, muito provavelmente apresentada numa aula de filosofia de Francisco Mendoça, salientamos alguns aspectos: a preocupação do mestre em documentar as suas afirmações com a citação rigorosa, em apresentar diferentes pontos de vista, sem por isso deixar de dizer com qual se identifica e porquê, e a importância dada à 'autoridade' da experiência. Não deixa de ser surpreendente esta última afirmação que classifica como 'de maior peso' o argumento da experiência anatómica.

Esta é apenas uma breve questão, entre muitas que foram recolhidas e compiladas por Francisco Machado no Viridarium. Um estudo mais extenso e profundo, estudo necessariamente interdisciplinar, desta obra, muito citada mas talvez menos conhecida, resultaria seguramente num valioso contributo para a história do ensino e do saber em Portugal.

CARLOTA MIRANDA URBANO

${ }^{6}$ Anatomicus, a, um: 'que corta os membros'. 